\title{
Impact of lightning strike on economics of sheep and goat rearing in Tamil Nadu under field condition
}

\author{
T. Chandrasekar ${ }^{1 *}$, P. Karu², A. Varun ${ }^{3}$, D. Balasubramanyam ${ }^{4}$ and M. A. Prakash ${ }^{5}$ \\ ${ }^{1}$ Livestock Farm Complex, Veterinary College and Research Institute, Theni - 625 602, Tamil Nadu, \\ India; ${ }^{2}$ ICAR-Network Project on Sheep Improvement-Madras Red Field Unit, Post Graduate Research \\ Institute in Animal Sciences, Kattupakkam - 603 203, Tamil Nadu, India; ${ }^{3}$ Pig Breeding Unit, Post \\ Graduate Research Institute in Animal Sciences, Kattupakkam - 603 203, Tamil Nadu, India; \\ ${ }^{4}$ Veterinary College and Research Institute, Theni - 625 602, Tamil Nadu, India; ${ }^{5}$ Krishi Vigyan \\ Kendra, Kattupakkam - 603 203, Tamil Nadu, India
}

\begin{abstract}
Lightning is a high energy luminous electrical discharge mostly accompanied by thunder during rainy seasons. During rainy days, more than $\mathbf{7 0 \%}$ of peoples or livestock are affected by lightning strike due to standing under the tree. The current paper reported the effect and economic losses of lightning strike in Tamil Nadu, India. The reported flock had 155 sheep and 32 goats. About 23 sheep and 5 goats died in the lightning strike. Other effects of lightning strike was total eye blindness, unilateral eye blindness, fore legs in-coordination, hind legs in-coordination, edematous swelling on lateral abdominal region and anorexia. Highest mortality $(34.78 \%)$ was observed in pregnant ewe. The total eye blindness and unilateral eye blindness in sheep were about $1.29 \%$ and $1.94 \%$, respectively which were not recoverable. The hind legs were affected more common in comparison to fore legs in lightning strike in sheep and goat. The fore legs in-coordination, edematous swelling in lateral abdominal region and anorectic animals were mostly recovered within three days of post lightning period. The total economic losses were about Rs. 1,26,000/- $(17.92 \%)$ in sheep and Rs. 34,500/- $(18.75 \%)$ in goat flock. The total economic losses due to lightning was Rs. 1,60,500/- (18.09\%) in sheep and goat flock. It concluded that the lightning strike caused severe mortality particularly to the pregnant animal, physical deformities which in terms affect the economics of sheep and goat production in field condition.
\end{abstract}

Key words: Economic loss, Goat, Lightning strike, Sheep, Tamil Nadu

Lightning is a high energy luminous electrical discharge mostly accompanied by thunder during rainy days which is very common during rainy season and latter part of summer. The power of lightning is estimated to be between 10,000 and 2,00,000 Ampere of current with estimated voltage ranging from 20 million to 1 billion Volts (Norman et al., 2001). Livestock are more vulnerable to be affected by lightning as they are usually placed outdoor even under thunderstorm conditions. Animals such as elephant, cattle, horses, sheep, goat, donkeys, etc. are more common to receive lightening injuries since these animals have large separation between their front and hind feet. This leads to build up of dangerous potential difference between front and hind feet, in the event of nearby lighting (Gomes, 2012). More than $70 \%$ peoples or livestock were affected by lightning mostly due to standing under the tree during rainy/ monsoon seasons (Mid-Monsoon lightening report, 2019).

There are several case studies were published on lightning effects in domestic and wild animals which mainly focused on medical aspects of lightning injuries, technically viable solutions to minimize the lightning hazards with some precautionary measures (Boeve et al., 2004; Evans et al., 2012; Gomes, 2012; Shankar and Braddon, 2015). Only few papers were reported the effect and economic impact of lightning under field condition in animals. Traceable literatures are available on the post lighting effects in animals. The main object of 
this paper was an attempt to investigate the post lightning effect and economic impact of lightning in affected sheep and goat flock under farmers' field in Tamil Nadu, India.

The flock of Mr. Rajesh, Vaiyavur village, Kancheepuram district, Tamil Nadu was registered with the Indian Council of Agricultural Research funded "Network Project on Sheep Improvement-Madras Red Field Unit". He had 155 (3 rams, 45 pregnant ewes, 30 non-pregnant ewes, 25 yearlings and 52 lambs) and 32 (1 buck, 5 pregnant does, 13 non-pregnant does, 5 yearlings and 8 kids) number of Madras Red sheep and nondescriptive goats in his flock. Heavy rain was started around 1.45 PM on 09.10.2020 and his entire flock tried to escape from communal grazing land. Unfortunately a group of animal was accommodated under the palm tree with surrounding bushes. However, other animals and shepherd were standing some distance from that palm tree, where a flash of lightning happened around 3.15 PM. The investigation was carried out at $7.30 \mathrm{pm}$ on the lightning day and the effect of post lightning was carried out through personnel interview with the owner and on examination of the affected flock. Post lightning effects like age wise mortality, total eye blindness, unilateral or one side eye blindness, edematous swelling on lateral abdominal region and anorexia were recorded for next three days. Animals with total eye blindness, unilateral eye blindness, hind legs in-coordinated sheep and goat were sold as they failed to recover after three days post lightning. Through those data, the post lightning complications, total economic loss and total economic loss percentage of lightning strike in sheep and goat flocks were calculated. Number of animals and percentage of animals affected by lightning strike in sheep and goat flock were presented in Table 1. It was observed that $14.84 \%(23)$ and $15.63 \%$ (5) mortality were recorded among the sheep and goat flock during the sudden lightning (Fig. 1). The pregnant ewe's mortality percentage $(34.78 \%)$ was

Table 1. Total number of animals and percentage of animals affected by lightning strike in sheep and goat flock

\begin{tabular}{llcccc}
\hline Sl. & \multicolumn{1}{c}{ Particulars } & & \multicolumn{2}{c}{$\begin{array}{c}\text { Total number of } \\
\text { animals affected by } \\
\text { No. }\end{array}$} & \multicolumn{2}{c}{$\begin{array}{c}\text { Percentage of animals } \\
\text { affected by lightning } \\
\text { strike }\end{array}$} \\
\cline { 2 - 6 } & & Sheep & Goat & Sheep & Goat \\
\hline 1. & Total number of animals in the flock & 155 & 32 & 100 & 100 \\
2. & Death due to lightning strike & 23 & 5 & 14.84 & 15.63 \\
& i. Pregnant ewes/does & 08 & 00 & 34.78 & 0.00 \\
& ii. Dry ewes/does (non-pregnant) & 04 & 03 & 17.39 & 60.00 \\
& iii. Yearlings & 05 & 02 & 21.74 & 40.00 \\
& iv. Lambs/kids & 06 & 00 & 26.09 & 0.00 \\
\hline & $\quad$ Post lightning effects & & & \\
\hline 3. & Total eye blindness & 02 & 00 & 1.29 & 0.00 \\
4. & Unilateral eye blindness & 03 & 00 & 1.94 & 0.00 \\
5. & Fore legs in-coordination & 03 & 01 & 1.94 & 3.13 \\
6.. & Hind legs in-coordination & 07 & 03 & 4.52 & 9.38 \\
7. & Edematous swelling on lateral abdominal & 03 & 00 & 1.94 & 0.00 \\
& region & & & & \\
8. & Anorexia in day 1 & 79 & 17 & 50.97 & 53.13 \\
9. & Anorexia in days 2 & 41 & 05 & 26.45 & 15.63 \\
10. & Anorexia in days 3 & 15 & 01 & 9.68 & 3.13 \\
\hline
\end{tabular}


higher as compare to dry/non-pregnant ewes $(17.39 \%)$ in the total lightning death. The yearlings and lamb mortality percentage were 21.74 and 26.09 , respectively in total sheep death. The non-pregnant does and yearlings' goat mortality percentage were 60 and 40, respectively. Observations indicate that mortality in pregnant animals were high since these animals had less chance to escape from natural calamities such as lightning strike followed by lamb, yearlings and dry ewes.

The chance of total eye blindness (Fig. 2) and unilateral eye blindness was about $1.29 \%$ and $1.94 \%$, respectively in sheep. This blindness was permanent and not able to recover. The fore legs in-coordination and hind legs in-coordination were $1.94 \%, 4.52 \%$ and $3.13 \%, 9.38 \%$ in sheep and goat, respectively.
Results showed that the hind legs were more commonly affected than fore legs in lightning strike. Edematous swelling on the lateral abdominal region was recorded in $1.94 \%$ of sheep. The fore legs in-coordination and edematous swelling in lateral abdominal region were recovered within 3 days of post lightning period. More than $50 \%$ of the sheep and goats had anorexia. From the results it was clear that anorexia in sheep and goats were the major post effect of lightning strike. Anorexia was also frequently recovered within 3 days of post lightning period.

The economic losses of lightning in sheep and goat flock were presented in Table 2 . The total loss by mortality was about Rs. 1,09,000/- in sheep and Rs. 31,000/- in goat flock. The pregnant sheep lightning death loss

Table 2. Economic losses due to lightning strike in sheep and goat flock

\begin{tabular}{|c|c|c|}
\hline \multirow[t]{2}{*}{ Particulars } & \multicolumn{2}{|c|}{ Lost amount (Rs.) } \\
\hline & Sheep & Goat \\
\hline \multicolumn{3}{|l|}{ 1. Loss due to lightning death: } \\
\hline i. Pregnant ewes/does@ Rs. 7,000/sheep \& Rs. 8,000/ goat & 56,000 & - \\
\hline ii. Non-pregnant ewes/does@ Rs. 6,000/sheep \& Rs. 7,000/goat & 24,000 & 21,000 \\
\hline iii. Yearlings@ Rs. 4,000/sheep \& Rs. 5,000/goat & 20,000 & 10,000 \\
\hline iv. Lamb/kids@ Rs. 1,500/sheep \& Rs. 2,000/goat & 9,000 & - \\
\hline Total loss by lightning death & $1,09,000$ & 31,000 \\
\hline 2. Loss due to total eye blindness@ Rs. 3,000 in each sheep (adult) & 6,000 & - \\
\hline $\begin{array}{l}\text { 3. Loss due to unilateral eye blindness@ Rs. 2,000 in each } \\
\text { sheep (adult) }\end{array}$ & 6,000 & - \\
\hline \multirow{3}{*}{$\begin{array}{l}\text { 4. Loss due to hind legs in-coordination@ Rs. 2,500 in each } \\
\text { sheep (adult) \& Rs. 3,500 in each goat (adult) } \\
\text { Grand total } \\
\text { Total loss in sheep and goat flock }\end{array}$} & 5,000 & 3,500 \\
\hline & $1,26,000$ & 34,500 \\
\hline & \multicolumn{2}{|c|}{$1,60,500$} \\
\hline \multicolumn{3}{|l|}{ 5. Cost of total population: } \\
\hline i. Rams/bucks@ Rs. 10,000/sheep \& Rs. 12,000/goat & 30,000 & 12,000 \\
\hline ii. Pregnant ewes/does & $3,15,000$ & 40,000 \\
\hline iii. Non-pregnant ewes/does & $1,80,000$ & 91,000 \\
\hline iv. Yearlings & $1,00,000$ & 25,000 \\
\hline v. Lambs/kids & 78,000 & 16,000 \\
\hline Grand total & $7,03,000$ & $\mathbf{1 , 8 4 , 0 0 0}$ \\
\hline 6. Cost of total population in sheep and goat flock & \multicolumn{2}{|c|}{$8,87,000$} \\
\hline 7. Economic loss percentage in total population & $17.92 \%$ & $18.75 \%$ \\
\hline $\begin{array}{l}\text { 8. Total economic loss percentage in sheep and goat flock due } \\
\text { to lightning }\end{array}$ & \multicolumn{2}{|c|}{$18.09 \%$} \\
\hline
\end{tabular}


Indian Journal of Animal Health, June, 2021

Effect of lighting strike on sheep and goat flock
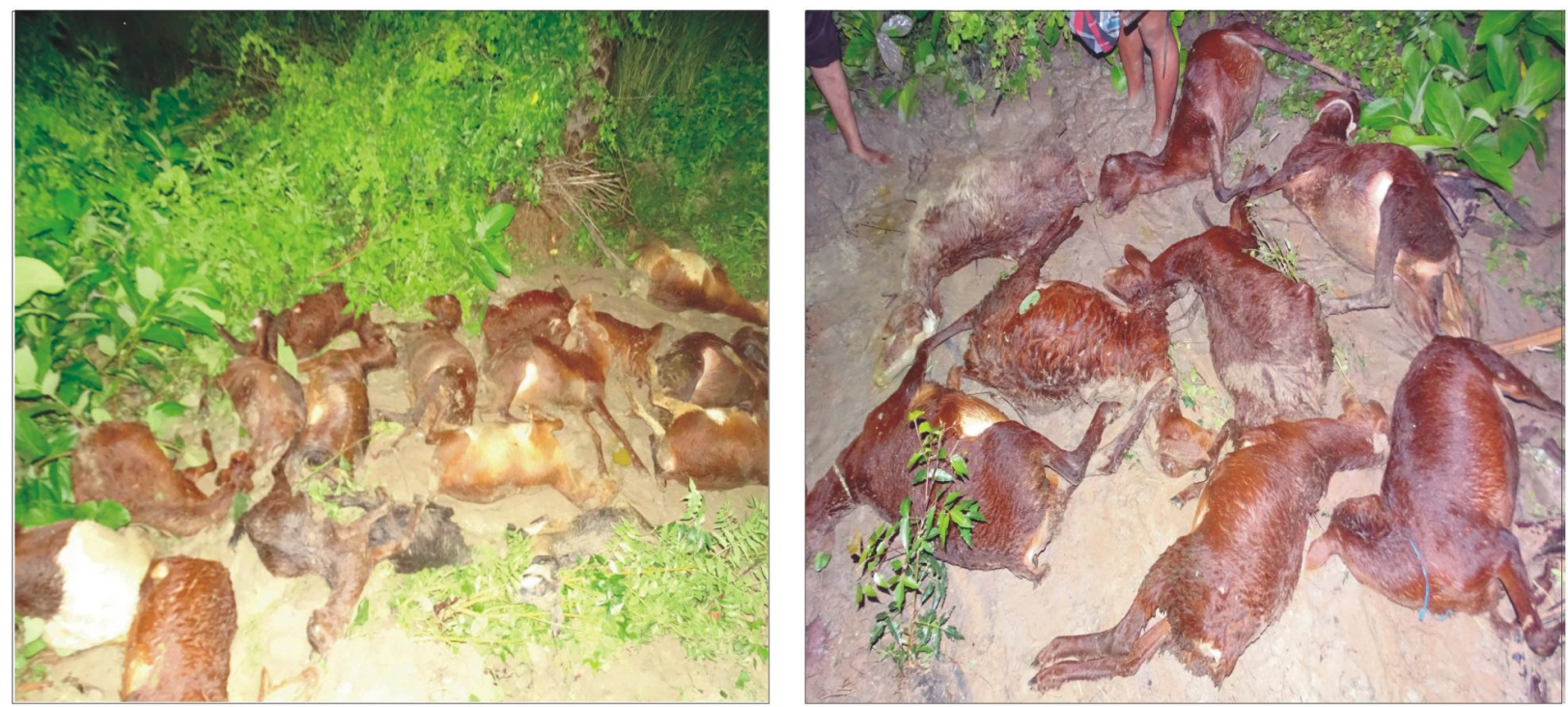

Fig. 1. The death carcass of sheep and goat due to lightning strike

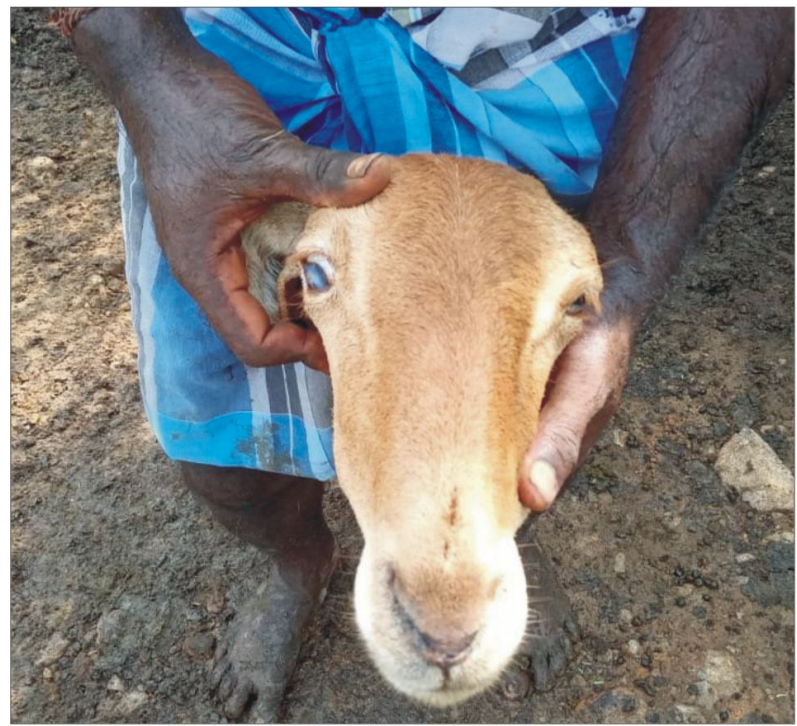

Unilateral eye blindness

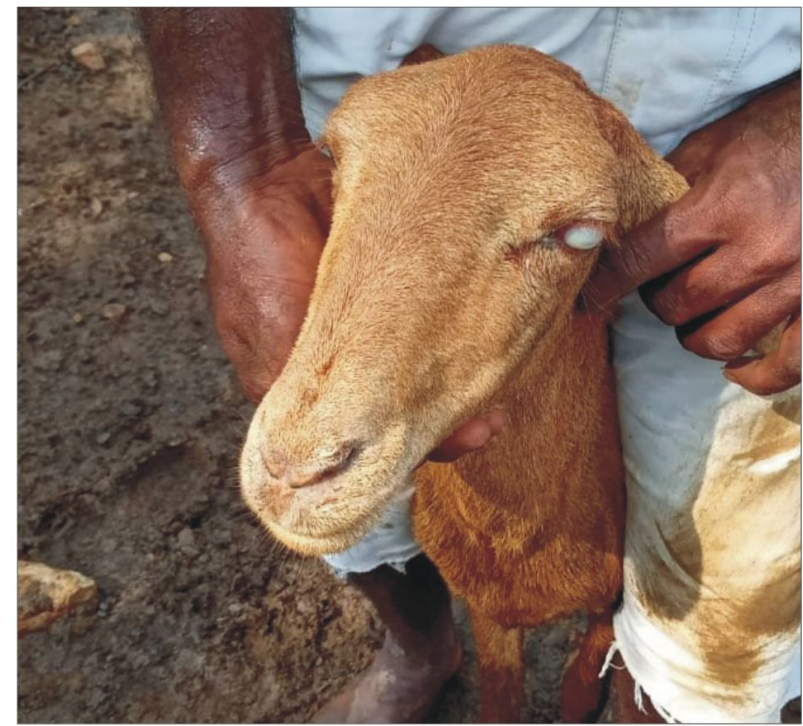

Total eye blindness

Fig. 2. The eye blindness of sheep due to the effect of lightning strike 
was more when compare to others animals death. The total eye blindness and unilateral eye blindness caused the economic loss of Rs. 6,000/- each in sheep flock. Similarly, hind legs in-coordination caused the economic loss of Rs. 5,000/- for sheep and Rs. 3,500/- for goat flock. Results showed that the mortality due to lightning caused major economic loss in the sheep and goat flock. It coincides with earlier report, the loss of animals cause much higher economical impact than property damage (Gomes, 2012). The cost of total population was Rs. 7,03,000/- in sheep and Rs. 1,84,000/- in goat flock. The grand total loss due to lightning was about Rs. 1,26,000/- and Rs. 34,500/- in sheep and goat flock respectively. It was $17.92 \%$ in sheep and $18.75 \%$ in goat flock of total economics. The total economic loss due to lightning in sheep and goat flock was Rs. $1,60,500 /$ - . It was $18.09 \%$ of the total economics of the sheep and goat flock. It indicated that the lightning strike caused huge economic losses to the farmer under field

\section{REFERENCES}

Boeve MH, Huijben R, Grinwis G and DjajadiningratLaanen SC, 2004. Visual impairment after suspected lightning strike in a herd of HolsteinFriesian cattle. Vet Rec, 154(13): 402-404, doi: 10.1136/vr.154.13.402

Evans PM, Micki DA and Dubielzig RR, 2012. Ocular lesions following suspected lightning injury in a horse. Vet Ophthalmol, 15(4): 276-279

Gomes C, 2012. Lightning safety of animals. Int J Biometeorol, 56(6): 1011-1023, doi: 10.1007/ s00484-011-0515-5

Mid-Monsoon lightening report, 2019. Lightning resilient India campaign, a joint initiative by condition. No references were found in previous study among the total economic losses due to lightning strike in sheep and goat flock.

The effect of lightning strike was mortality, total eye blindness, unilateral eye blindness, fore legs in-coordination, hind legs in-coordination, edematous swelling on lateral abdominal region and anorexia. The mortality due to lightning was caused major economic loss in the sheep and goat flock as compared to other impact. Overall, the lightning strike causes much more economic losses and affects the livelihood of the sheep and goat farmers under field condition.

Conflict of interest: Authors have no conflict of interest in this study.

\section{ACKNOWLEDGEMENT}

The authors thank the ICAR, New Delhi and Project Co-ordinator (SB), NWPSI, CSWRI Avikangar for providing necessary facilities for conducting the study.

Climate Resilient Observing Systems Promotion Council (CROPC), Indian Meteorological Department, Ministry of Earth Science, Government of India and World Vision India, pp 20

Norman ME, Albertson D and Younge BR, 2001. Ophthalmic manifestations of lightning strike. Surv Ophthalmol, 46(1): 19-24, doi: 10.1016/ s0039-6257(01)00232-6

Shankar R and Braddon E, 2015. Flock and herd: Lightning strike in the Riverina. Available in: http://www.flockandherd.net.au/cattle/reader/ lightning-strike-riverina.html 